\title{
Participatory Community-Driven Development and Sustainable Rural Development in Nigeria
}

\author{
Ime Okon Utuk \\ Department of Economics Faculty of Social and Management Sciences Akwa Ibom State University Obio Akpa \\ Campus Nigeria.
}

\begin{abstract}
Since the mid-1990s, community driven development has emerged as one of the fastest growing investments by donor agencies. It emerged against the conventional top-down syndrome which never had any sustainable impact on the living conditions of community members especially in rural Nigeria. Participatory development is a way of learning from and with community members to investigate, analyse, and evaluate constraints and opportunities, and make informed and timely decisions regarding development projects. The key elements of a successful community driven development projects are participation, sustainability and an enabling policy environment. Therefore, the micro-projects programme embarked upon by the European Union in the Oil producing areas of the Niger Delta region of Nigeria was evaluated based on the key elements. It was realized that the non-participation of all the sub- groups in the communities, unsustainaility plan, and lack of enabling policy environment led to the abandonment of some of the projects in some communities. Therefore, the good intention of the donor agencies of reducing poverty in the rural communities, reaching out to the disadvantage groups, easing social tension and ensuring sustainable development of the rural areas have been negated.
\end{abstract}

Keywords: Disadvantage groups, enabling policy environment, oil producing areas of the Niger Delat region of Nigeria, participation, sustainability.

\section{Introduction}

Since the mid-1990s, community driven development has emerged as one of the fastest growing investments by donor agencies. This continued investment in community driven development has been driven mostly by a demand from donor agencies and developing countries for large - scale, bottom up and demanddriven, poverty reduction projects that can increase the institutional capacity of small communities for self development.

Community driven development emerged against the conventional top-down syndrome which never had any sustainable impact on the living conditions of community members especially in rural Nigeria. The project instead, develops a more people centered and inclusive bottom up development approach[1]. This development approach gives voice to community members or beneficiaries to have absolute control over resources and decisions affecting them.

The potential gains from community driven development are large. It has the explicit objective of reversing power relations in a manner that creates agency and voice for poor people, allowing them to have more control over development assistance [2]. This is expected to make the allocation of development funds more responsive to their needs, improve the targeting of poverty programmes, make government more responsive, improve the delivery of public goods and services and strengthen the capabilities of the citizenry to under-take self-initiated development activities.

\subsection{Participatory Community Driven Development}

\section{Conceptual Issues}

In the 1950s and 1960s, it was widely believed that all it took to improve the economic situation of developing countries was financial inputs and modern technology. The Green Revolution is a typical example of such a transfer of technology from the modern industrialized countries to the poorer nations. In the 1970s, however, it became clear that the transfer of technology did not solve the problems of most people in developing countries. Development workers and researchers began to understand the complex relationship between environment, economy, culture and politics in rural societies. They therefore began to view and tackle the various aspect of rural life as part of an integrated system. It was realized that systems, for example the complex agricultural systems found in most developing countries developed through adaptive change rather than by linear progress, that is dynamic and its parts interacts by influencing each other [3]. It is not possible to effect a change in one element of the system in isolation without affecting the other parts. Consequently, the system as a whole has to be understood in order to identify and help bring about desired changes. 
Along with the emergence of this new development, new research techniques were developed to achieve a more comprehensive understanding of the complexities of rapidly changing and highly uncertain societies and communities. One of the new research methods was participatory rural development. This research method embodies the principle that different people perceive and understand the reality in different ways. Participatory development is characterized by an applied, holistic and flexible approach of progressive learning conducted by multidisciplinary teams, who emphasized community participation.

Participatory development is a way of learning from and with community members to investigate, analyse, and evaluate constraints and opportunities, and make informed and timely decisions regarding development projects. In its simplest form, participatory development is one which carries the rural people along at every stage of the development process. In this method, all those who have interest play an active role in decision making and in all activities which affect them. They are involved in the identification and prioritization of activities to be undertaken, decision-making, planning, implementation, monitoring and evaluation.

\subsection{Literature Review on Participatory Community Driven Development}

The literature on community driven development is extensive but scattered across several disciplines, including rural sociology, agricultural economics, environmental sciences, public administration, anthropology, business administration, and finance [4].

However, most of the recent literature, dating from the late 1990s has not been published in peer reviewed academic journals and is difficult to access. An earliest attempt was made by [5]. In his notion of village self-reliance and small scale development, which according to him was an antidote to the corrosive effects of modernization and colonial rule. Another influential literature was that of Freire [6], who argued that the oppressed needed to unite to find a way to improve their own lestinies. These ideas led to a first wave of participatory development in the 1950s, which by 1960 had spread to more than 60 countries in Africa, Asia and Latin America.

By the mid 1980s, critics of the "big development" were complaining that many large-scale government initiated development programmes, from schooling to health, credit to irrigation systems, were performing poorly, while rapidly degrading common pool resources were creating significant negative environmental and poverty impacts. These complaints reawakened interest in the local management of resources and decisions. The participatory development movement led by Chambers [7] was important in applying these ideas to small scale development in ways that would allow the poor to be informed participants in development, with external agents acting mainly as facilitators and sources of funds.

Sen's [8], influential effort to shift the focus of development from material well-being to a broad based capability approach also deeply influenced the development community. Central to this approach were strategies to empower poor people, an agenda taken on by the World Bank and other donors as part of their response to critiques of top-down development. Arguments for participatory development as advocated by Chambers and others, led to the inclusion of participation as a crucial means of allowing the poor to have control over decisions.

The inclusion of participatory elements in large scale development assistance was included in the World Bank in their social investment funds [9] and other forms of assistance. Initially, focusing on targeting, these projects have moved toward a more holistic attempt at inducing participation through institutions that organize the poor and build their capabilities to act collectively in their own interest [10]. What emerges from the literature review is that participatory community driven development grants decision making powers to community groups and residents in the design of interventions aimed at improving standards of living and the allocation of resources to achieve agreed upon goals. It is also a means of providing small scale infrastructure services, better organization of economic and natural resource management activities, empowering poor people, enhancing democratic governance and accountability, and improving the security of the poorest elements of the rural community.

\subsection{The Meaning of a Community}

Participatory projects are typically implemented in a unit referred to as a community. A community is therefore, defined as a group of people residing in the same region and under the same government. It is also defined as the locus where all members of a group of people, having some form of collective claim over a territory and recognizing some form of collective governance, can be given the opportunity to influence decisions in matters of public choice that affect their livelihood.

The interest and aspiration of the communities till today remain largely unfulfilled. The reason is that governments in the developing countries are actually not meeting the needs of the community people. The rural development programmes embarked upon by the government to transform the rural economy have minimal impact on the rural communities. Infact, on the whole, the role played by government at various levels national, state and local have in some or many ways failed at addressing the key issues in the rural communities. 


\section{The Concept of Sustainable Rural Development}

Environmentalists have used the term sustainable development in an attempt to clarify the desired balance between economic growth on the one hand and environmental preservation on the other [11]. Hence, sustainable development refers to meeting the needs of the present generation without compromising the needs of future generations. Furthermore, according to Jhingan [12], sustainable development emphasizes the creation of sustainable improvements in the quality of life of all people through increases in real income per capita, improvements in education, health and general quality of life and improvements in quality of natural environmental resources. Thus sustainable development is closely linked to economic development. It is a situation in which economic development does not decrease over time. Sustainable development is development that is everlasting and contributes to the quality of life through improvements in natural environments.

The importance of rural development can better be appreciated by noting that 75 percent of the total population of Nigeria lives in the rural areas, and these rural majorities are small scale farmers who produce about 90 percent of the total food requirement of the nation [13], [14].

It is universally acknowledged that rural areas are very important to a nation. They serve as the base for the production of food and fibre. They are also the major sources of capital formation for a country and a principal market for domestic manufactures, [15]. In general terms, the rural areas engage in primary activities that form the foundation of any economic development.

Yet, despite the importance of the rural areas, they have been neglected for long. Usually, there is absence of infrastructure like (water, electricity supply and motorable roads) which improve quality of life. Indeed, the ongoing neglect of rural areas continues to widen the gap between the rural and urban dwellers regarding the levels of social and economic opportunities, physical development and available infrastructural services.

Development planners have recognized the fact that the upliftment of the rural economy, vis-à-vis the rural poor and backward masses is a precondition for the overall development of the country. Successive development plans of the country, therefore emphasized on rural development. But in the implementation of the planned objectives, the success was rather limited due to some constraints, at the top of which was the lack of participation of the stakeholders-the rural dwellers, who hardly had any influence and control over development initiatives.

Most of the rural development programmes embarked upon by the government have scarcely had any rural inputs at the planning stages and have therefore never reflected the felt-needs of the rural people. In fact, many of the programmes have never reached the rural people, nor have their impacts being felt by them. There is now an urgent need for an approach to rural development that requires the involvement and participation of the rural people at every stage of the rural development process to ensure sustainable development of this sector.

\section{A Case Study of the Impact of Community Driven Development Initiatives}

This is a case study of the European Union funded micro-projects programme in nine states of the Niger Delta region of Nigeria. The Niger Delta is the main oil producing area of Nigeria. It constitutes nine states and provides most of the 95 percent of the government revenues which is being derive from crude oil production [16]. However, many communities in the area are amongst the least developed in the country. In December 1999, the European commission adopted a Micro-Projects Programme (MPP3) for three states of the Niger Delta: Bayelsa, Delta and Rivers States. However, following the success of MPP3, a further microprojects Programme (MPP6) was commissioned in the remaining six oil producing states of Abia, Akwa Ibom, Cross River, Edo, Imo and Ondo States. The programme aimed at helping to improve the living standards in poor settlements of the nine states on a sustainable basis and thus contribute to poverty reduction and easing social tension in the region. The project also aimed at improving the quality of access to basic physical and social infrastructure, income generating opportunities and micro-finance services on a sustainable basis. This was mainly in the areas of water supply and sanitation, rural roads, transport, health and education facilities. It also supported income generation activities such as oil Palm processing Mills, Cassava Processing Mills and micro-finance. Furthermore, the project also engaged local civil society Organizations (CSOs) and Community Based Organisations (CBOs). Their capacity to design, manage, implement and monitor participatory pro-poor development activities was developed.

\subsection{The Procedure Used in Micro-Projects Development by the European Union Programme}

This section describes the various procedures used by the European Union in Micro-projects development to ensure participatory community driven development.

4.1.1 Community Sensitization: Since the CSOs and CBOs have the ability and capacity to reach out to the underserved and difficult to reach areas, they were assigned the responsibility of penetrating the rural communities to mobilize and sensitize the rural dwellers. After a series of visits to a particular community to 
create awareness, the CSO or CBO arrange for a meeting with the community members. The expectation is that a cross section of the community members will be present at the meeting. At the meeting, one project which is the most pressing need of the community is selected for development through pair wise ranking method. At this meeting too, the members of the project management Committee (PMC) are selected. From then onward and throughout the entire life of the project cycle, the subsequent meetings of the CSO or CBO with the community is through the members of the Project Management Committee (PMC).

4.1.2 Concept Note and Need Assessment Form: The CSO or CBO with the assistance of the PMC members will produce what is called a concept note. This document highlights the historical background of the community, problem statement, the cost of the project, community contribution and sustainability plan. The Need Assessment form also provides information on the initial situation in the community. The information will act as a base-line data for impact assessment after one year of project completion.

4.1.3 Identification/Verification of Claims: The project team leader will visit the community to verify/ascertain the claims the $\mathrm{CSO}$ and the PMC members have put down on the concept note. When this is done, the CSO or $\mathrm{CBO}$ can then produce the project proposal and Bill of Quantities (BOQ). The Bill of Quantities shows the activities that will be carried out and the amount of money needed for the execution of each of the activities until completion.

4.1.4 Project Sustainability Plan: The Community through the CSO or CBO and the PMC members submit to the European Union Team Leader what is called Project Sustainability Plan (PSP). This document highlights the plans by the community on how they intend to manage and sustain the project throughout its entire life span.

4.1.5 Community Contribution: The cost of each project was shared between the European Union and the community. The European Union contribution was seventy five percent, while that of the community was twenty five percent. The community had to submit to the European Union Team leader the items they would contribute to make up the twenty five percent.

4.1.6 Capacity Building: The members of the CSOs and CBOs, the main facilitators of the projects were trained on European Union Project implementation procedures, community engagement, proposal writing, concept notes writing, accounting methods and records keeping. Moreover, each of the projects were designed with an in-built training programmes for the community members. This was done with a view to improving the capacity of the benefiting communities on project management, maintenance and records keeping so as to ensure the sustainability of the projects.

4.1.7 Continuous Stakeholders Meeting: The CSO or the CBO were required to call for continuous stakeholders meeting at the community level. The aim of the meeting was to resolve conflict, assess the level of work done, community contribution and the level of community participation.

The above procedures were adopted by the European Union programme on their Micro-projects development. The methods were adopted with a view to ensuring sustainable rural development. Since this approach is based on the needs of the rural communities, it is democratic in philosophy and procedure and places the welfare of the rural people above every other consideration.

\section{Impact Assessment}

The key elements of a successful community driven development projects are participation, sustainability and an enabling policy environment. Therefore, the micro-projects programme embarked upon by the European Union in the Oil producing areas of the Niger Delta region of Nigeria will be evaluated based on these key elements.

5.1 Participation: The cornerstone of community based development initiatives is the active involvement of members of a defined community in project design and implementation. Participation is expected to lead to better designed projects, better targeted benefits, more cost-effective and timely delivery of project inputs, and more equitably distributed project benefits with less corruption and other rent seeking activities. It is unfortunate that in the micro-projects programme of the European Union, the communities did not derive the benefits as envisioned by the donors. This is because in most of the communities, the disadvantage groups which comprised women, youths and the very poor people did not know about the existence of such projects in their communities. From the design, planning and to implementation, they hardly had any idea about the project. Thus, those who were to benefit more from the project were not carried along. 
Furthermore, the constitution of the project management committee (PMC) in most communities was lopsided. The appointment favoured the elite, relations and kinsmen of the village head, living behind the poor and the voiceless. Hence, clearly projects benefits were being appropriated by community leaders and little attempts was made to include the disadvantage groups.

5.2 Sustainability: For community driven development projects to succeed and continue over time, the issue of how sustainability is achieved becomes critical. The greatest problem of most community driven rural development is financial viability. Sustainability requires significant community contributions, both in cash and in kind. Unfortunately, the communities were typically too poor to make large cash contributions. In the various communities EU intervened, their sources of funds in the sustainability plan they presented included, quarterly levy of the community members, the sell of oil palm fruits and user charges in the case of water and sanitation projects, oil palm processing mills and cassava processing mills. The money was needed for purposes of repairs and maintenance of the projects to ensure sustainability. The expectation from these sources of funds was not realized and as a result, the projects deteriorated and becames of limited or no use in the lapse of a few years.

5.3 Enabling Policy Environment: For a project to make any appreciable impact, either at the national, state or local community level, there must be a condusive and enabling policy environment free from tension and conflict. In the various communities that benefited from the E.U intervention, there was escalating tension and conflict. There was a large scale conflict between the CSOs or CBOs and members of the Project Management Committee (PMC). The members of the project management committee were accusing the CSOs and CBOs of not carrying them along in the implementation of the projects. On the other hand, the CSOs and CBOs were accusing the PMC members that they were purchasing inferior items for the execution of the projects. Moreover, they were diverting funds and materials for the execution of the projects for their private use. In addition, the community members were accusing the PMC members of not carrying them along from the inception, planning and implementation of the project. The E.U team leader had to be traveling to nearly all the communities that benefited from the intervention to settle dispute. The adverse influence of conflict limited or negated the positive impact of intervention at the community levels. The combined effects of all these problems, non-participation of all the subgroups in the community, unsustainability plan and a lack of enabling policy environment led to the abandonment of some of the projects in some communities. The worse affected was water and sanitation projects, oil palm processing mills and cassava processing mills. Therefore, the good intention of the donor agency of reducing poverty in the rural communities, reaching out to the disadvantage groups, easing social tension and ensuring sustainable development of the rural areas has been negated.

\section{Conclusions}

Since the mid - 1990s, there has been continued investment in community driven development. This has been driven mostly by a demand from donor agencies and developing countries for large scale, bottom up and demand driven, poverty reduction projects that can increase the institutional capacity of small communities for self development. This development approach gives voice to community members or beneficiaries to have absolute control over resources and decisions affecting them.

The potential gains from community driven development are large. It has the explicit objective of reversing power relations in a manner that creates agency and voice for poor people, allowing them to have more control over development assistance.

The cornerstone of community based development initiatives lies in the active participation of community members, a robust sustainability plan and also enabling policy environment. The micro-projects programme embarked upon by the European Union in the Oil producing areas of the Niger Delta region of Nigeria was evaluated based on the above factors.

It was realized that the non-participation of all the sub-groups in the communities, unsustainability plan, and lack of enabling policy environment led to the abandonment of some of the projects in some communities. Therefore, the good intention of the donor agency of reducing poverty in the rural communities, reaching out to the disadvantage groups, easing social tension and ensuring sustainable development of the rural areas were negated.

\section{References}

[1]. W. B. Abdoul, Development driven by local communities: A sustainable instrument to alleviate poverty in Nigeria, International Fund for agricultural Development (IFAD) 2010, July - September.

[2]. G. Mansuri and V. Rao, Community-based and driven development: A critical review, The World Bank Research Observer, 19 (1), 2004, 1-33.

[3]. J. Brohman, Popular development: Rethinking the theory and practice of development (Oxford, Blackwell, 1996).

[4]. J. Dahl -Oslargaard, D. Moore, V. Ramirez, M. Wenner and A. Bonde, Community - driven rural development. What have we learned? Inter-American Development Bank. Sustainable Development Department Technical Papers Series, Washington, D. C. 2003. 
[5]. M. K. Gandhi, Village Swaraj (Ahmedabad, India Navivah Press, 1962).

[6]. P. Freire, Pedagogy of the Oppressed (Trans Myra Bergman Ramos, New York, Hercher and herder, 1970).

[7]. R. Chambers, Rural development: putting the first last (London, Longman, 1983).

[8]. A. K. Sen, Development as freedom (New York, Knopf, 1999).

[9]. D. Narayah and K. Ebbe, Design of social funds: participation, demand orientation and local organizational capacity, World Bank Discussion Paper 375, Washington, D. C. 1997.

[10]. D. Narayan, Empowerment and poverty reduction: A Sourcebook, The World Bank Economic Review, 15(2), 2002, 316 - 342.

[11]. M. P. Todaro and S. C. Smith, Economic Development (India, Pearson Education, 2004).

[12]. M. L. Jhingan, The economics of development and planning (India, Vrinda Publication (p) Ltd, 2004).

[13]. B. Olusegun, Assessment of river basin planning as a strategy for rural development (Enugu, Nigeria, Auto-century Publishers, 1991).

[14]. M. O. Igboeli, Self-help as a strategy for rural development: A critique, in M. S. Olisa and J. I. Obiakwu (Ed) Rural development in Nigeria: Dynamics and Strategy (Akwa, Nigeria, Mekslink Publishers, 1992).

[15]. D. Olatunbosun, Nigeria's neglected rural majority (Ibadan, Oxford University Press, 1975).

[16]. European Union Micro-Projects programme in six states of the Niger Delta; Participatory rural appraisal/participatory learning and action (PRA/PLA) Training Workshop for partner organizations, Owerri, Nigeria, 2005. 